\title{
Surgery in large anterior mediastinal mass: case series of Hospital Kuala Lumpur
}

\author{
Ammar Ahmad ${ }^{1}$, Narasimman Sathiamurthy ${ }^{1}$, Benedict Dharmaraj ${ }^{1}$, Narendran Balasubbiah ${ }^{1}$, \\ Diong Nguk Chai ${ }^{1}$, Amiruddin Nik Mohamed Kamil ${ }^{2}$, Muthukkumaran Thiagarajan ${ }^{3}$ \\ ${ }^{1}$ Thoracic Surgery Unit, Department of General Surgery, Hospital Kuala Lumpur, Kuala Lumpur, Malaysia; ${ }^{2}$ Department of Anaesthesiology, \\ Hospital Kuala Lumpur, Kuala Lumpur, Malaysia; ${ }^{3}$ Department of Radiotherapy and Oncology, Hospital Kuala Lumpur, Kuala Lumpur, Malaysia \\ Contributions: (I) Conception and design: All authors; (II) Administrative support: N Sathiamurthy; (III) Provision of study materials or patients: \\ A Ahmad; (IV) Collection and assembly of data: A Ahmad, B Dharmaraj, N Balasubbiah; (V) Data analysis and interpretation: All authors; (VI) \\ Manuscript writing: All authors; (VII) Final approval of manuscript: All authors. \\ Correspondence to: Ammar Ahmad, MD. Department of General Surgery, Hospital Kuala Lumpur, 50586, Kuala Lumpur, Malaysia. \\ Email: ammaraxmad@gmail.com.
}

Background: Mediastinal masses comprise of a wide variety of tumors and accounts for about $3 \%$ of tumors within the chest. Very few studies have been produced so far on large anterior mediastinal masses, as this pathology is infrequently encountered in clinical practice and tend to be asymptomatic until compression symptoms occur, which leads to mediastinal mass syndrome (MMS). The aim of this writing is to assess the surgical feasibility, approach, safety of resection and outcome in large anterior mediastinal masses.

Methods: A retrospective review was conducted on patients referred for mediastinal mass to the Thoracic Surgery Unit, Hospital Kuala Lumpur from October 2017 until March 2020 (30 months). Patients with evidence of primary anterior mediastinal mass measuring $>6 \mathrm{~cm}$ on contrast-enhanced computed tomography (CECT) of thorax and had undergone treatment in our centre were included. Data were analysed by proportions, means and standard deviations. Categorical data were expressed as percentage, whereas interquartile range was used to describe continuous variables.

Results: Out of 63 patients with anterior mediastinal mass, 16 (25.4\%) patients had anterior mediastinal mass larger than $6 \mathrm{~cm}$ and was included in the analysis. The average tumor size was $11.9 \mathrm{~cm}$. Five patients (31.3\%) had MMS. Twelve out of 16 patients were operated with $75 \%$ rate of clear tumor margin. There was no postoperative mortality recorded within 30 days of surgery.

Conclusions: Positive outcome of definitive surgery in this series suggests clinical feasibility with acceptable short-term safety. Multidisciplinary approach with adequate preoperative assessment, intraoperative preparation and short- and long-term postoperative care were key features to successful treatment of this disease.

Keywords: Large anterior mediastinal mass; mediastinal mass syndrome (MMS); thymoma; germ cell tumor; thoracotomy

Received: 23 June 2020; Accepted: 05 February 2021; Published: 25 May 2021.

doi: $10.21037 /$ ccts-20-119

View this article at: http://dx.doi.org/10.21037/ccts-20-119

\section{Introduction}

Mediastinal masses comprise of a wide variety of tumors and accounts for about $3 \%$ of tumors within the chest (1). The differential diagnoses may range from benign to highly malignant conditions, and delay in diagnosis may be fatal (2). Very few studies have been produced so far on large anterior mediastinal masses, as this pathology is infrequently encountered in clinical practices and tend to be asymptomatic until compression symptoms occur, which leads to 
mediastinal mass syndrome (MMS). This poses a huge challenge in the patient management during perioperative period. There are not many centres with multidisciplinary teams involving thoracic surgeons, thoracic anaesthetists, and oncologist to manage such challenging cases. We are fortunate to be a comprehensive thoracic surgery centre to manage such patients with favourable outcomes, comparable to other reported studies.

With this in background, the aim of this writing is to assess the surgical feasibility, approach, safety of resection and outcome in large anterior mediastinal masses. We present the following article in accordance with the STROBE reporting checklist (available at https://ccts. amegroups.com/article/view/10.21037/ccts-20-119/rc).

\section{Methods}

A retrospective review was conducted on patients referred for mediastinal mass to the Thoracic Surgery Unit, Hospital Kuala Lumpur from October 2017 until March 2020 (30 months). Patients were assessed on medical history, clinical examination, chest radiograph and contrastenhanced computed tomography (CECT) of thorax. Preoperative assessment included blood test ( $\alpha$-fetoprotein, $\beta-H C G, L D H)$, cardiac function evaluation and lung function test.

Patients with evidence of primary anterior mediastinal mass measuring $>6 \mathrm{~cm} \mathrm{(3)}$ on CECT thorax and had undergone treatment in our centre were included in the study. Those with poor functional status, not suitable for surgery or chemoradiotherapy were excluded from the study.

Patient's demographic information, signs and symptoms upon presentation, tumor details on imaging (e.g., location of tumor, size and local invasions), surgical interventions, postoperative care, length of hospital stay, tissue histopathology, complications and mortality rates were reviewed and documented from medical records. Thymic tumors were classified according to WHO Classifications of Tumors of Thymus. We do not regularly apply MasaokaKoga Classification in our general practice as it does not affect in our management and decision for surgery.

The study was conducted in accordance with Declaration of Helsinki (as revised in 2013). This is a retrospective analysis of cases that were operated in our hospital. The ethical approval and the informed consent for publication of this manuscript are waived from ethics committee.

\section{Statistical analysis}

Data were analysed by proportions, means and standard deviations. Categorical data were expressed as percentage, whereas interquartile range was used to describe continuous variables.

\section{Perioperative preparations}

Multidisciplinary meeting involving thoracic surgeon, anaesthesiologist, oncologist, respiratory physicians, pathologist, and radiologist will be held before every complex case of large mediastinal mass is subjected for surgery to discuss on preoperative optimization, intraoperative and postoperative managements, and possible complications.

\section{Surgical technique}

\section{Open surgery}

Open surgery is advocated for large mediastinal mass involving its surrounding structures like the chest wall, innominate vein, pericardium, pulmonary artery etc. The main goal is to remove the mass without breaching the capsule and resecting adjacent adhered structures while achieving safe control of the major vessels such as innominate veins, SVC, aorta, and pulmonary arteries. To achieve this, choice of approach would be sternotomy, thoracotomy or sternothoracotomy. Patients with mass confined to mediastinum will usually undergo sternotomy only. If the mass is extending beyond the mediastinum towards either hemithoraces, a sternothoracotomy will be considered during the surgery. Thoracotomy approach was considered if the mass was mainly in the hemithorax. Patient was positioned in supine under general anaesthesia with double lumen intubation. For sternotomy, sternum was incised with electric motor saw along the midline. In the case of thoracotomy, incision was made at $4^{\text {th }}$ or $5^{\text {th }}$ intercostal space by anterolateral or posterolateral incision, depending on the site of tumor. For sternothoracotomy, incision was extended from midline sternotomy into the anterolateral $4^{\text {th }}$ intercostal space to expose the tumor. Depending on the tumor position and extension, the pleural spaces may or may not be opened and the tumors were excised by en-bloc resection. Single or double chest drains with the size of 28-Fr were placed in all cases.

Uniportal video assisted thoracoscopic surgery (VATS) VATS excision was performed very selectively in large 


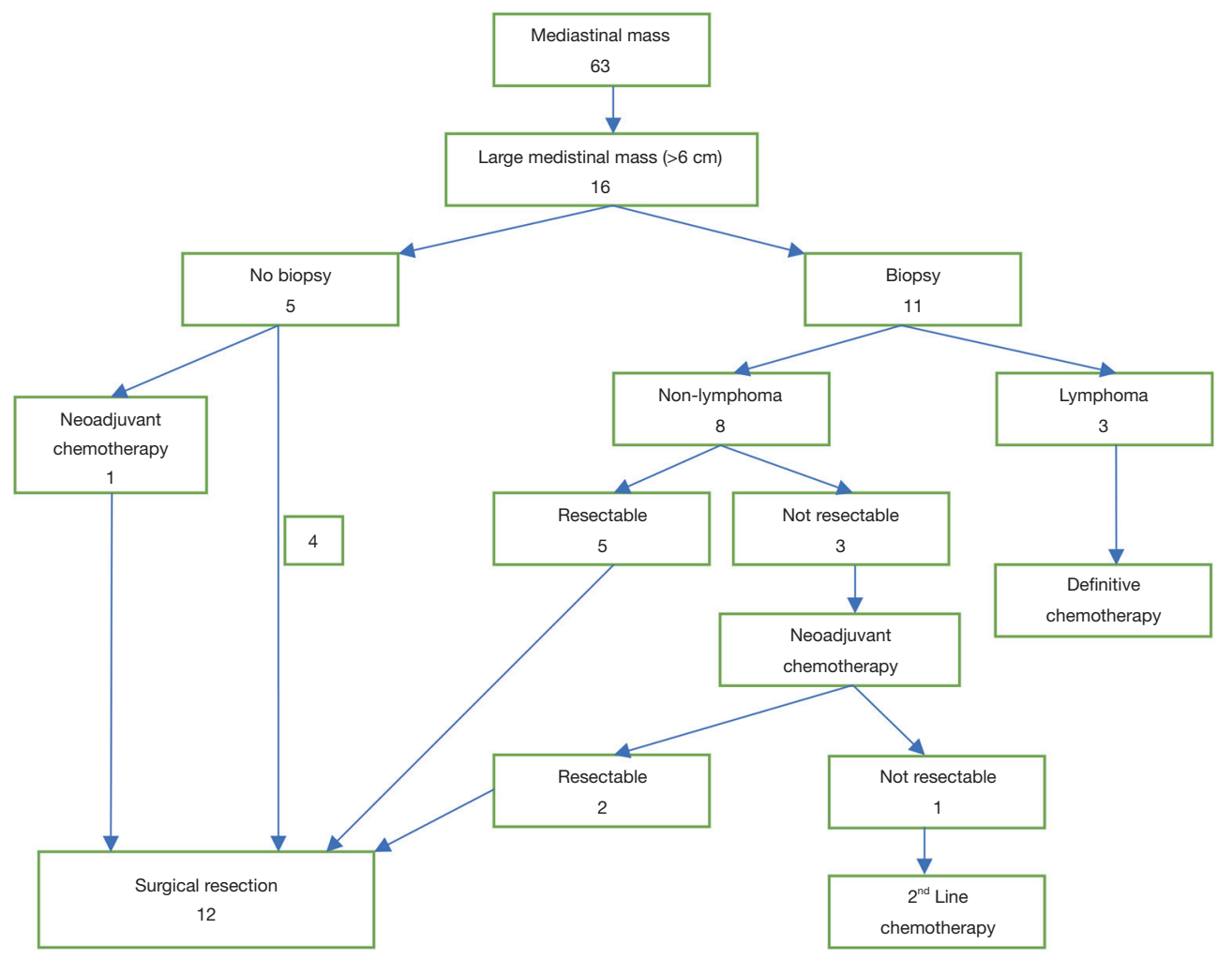

Figure 1 Treatment flowchart of patients with large mediastinal mass in the Thoracic Surgery Unit of Hospital Kuala Lumpur.

mediastinal mass which was not involving its surrounding structures with clear fat plane seen in CECT thorax. Surgery was performed under general anaesthesia with double lumen intubation. Patient placed in supine with ipsilateral arm abducted to expose the axilla. About $3 \mathrm{~cm}$ incision was made at the level of $4^{\text {th }}$ intercostal space at the anterior axillary line without rib spreading. The mediastinum was then approached through the pleural cavity.

In Subxiphoid uniportal VATS, patient was positioned with the pathology side elevated at $30^{\circ}$ angle, semi laterally. 3-4 cm incision made under subcostal notch and a subcostal tunnel was created behind the posterior costal arch. Mediastinal pleura was opened at the cardiophrenic angle to access the thoracic cavity. The excised mass was orientated according to the smallest dimension and delivered through the wound in an endo-bag to prevent spillage. Subxiphoid approach appeared to be a better option for retrieval of larger tumor as it is not confined to the intercostal space.

\section{Results}

In total, 63 patients were referred for mediastinal mass of various sizes and pathologies. Out of this, 16 (25.4\%) patients had anterior mediastinal mass larger than $6 \mathrm{~cm}$ and was included in the analysis (Figure 1). Table 1 shows the general characteristics of the studied patients and the tumors. Ten patients $(62.5 \%)$ had no underlying comorbid with ASA I classification. One patient was pregnant at 15 weeks period of gestation. We found that $81.2 \%$ of our patients with large anterior mediastinal mass were symptomatic with the commonest complaint being cough (37.5\%). Five patients (31.3\%) had MMS. Overall average tumor size was $11.9 \mathrm{~cm}$ (IQR, 8.2-15.8 cm), whereas the average tumor size was $17.0 \mathrm{~cm}$ (IQR, 13.0-19.1 cm) for patients with MMS.

Biopsy of the mass was performed in $11(68.8 \%)$ out of the 16 patients (Table 2). Histopathology of 3 patients that were biopsied turned out to be lymphoma and another was diagnosed as poorly differentiated thymic carcinoma. All four patients were subjected for definitive chemotherapy without surgery. Five patients with resectable mediastinal mass with characteristics of thymoma and nonseminomatous mediastinal germ cell tumor (NSGCT) in CECT thorax were not subjected for biopsy prior 
Table 1 Demographic characteristics

\begin{tabular}{|c|c|}
\hline Demographic characteristics & Values \\
\hline Age, years (mean, IQR) & $40.4(30.3-53.3)$ \\
\hline \multicolumn{2}{|l|}{ Sex, n (\%) } \\
\hline Male & $9(56.3)$ \\
\hline Female & $7(43.7)$ \\
\hline \multicolumn{2}{|l|}{ Comorbidity, n (\%) } \\
\hline Nil & $10(62.5)$ \\
\hline Diabetes mellitus & $2(12.5)$ \\
\hline Hypertension & $4(25.0)$ \\
\hline Dyslipidaemia & $3(18.8)$ \\
\hline Cerebrovascular disease & $1(6.3)$ \\
\hline Valvular heart disease & $1(6.3)$ \\
\hline Myasthenia gravis & $1(6.3)$ \\
\hline Red cell aplasia & $1(6.3)$ \\
\hline \multicolumn{2}{|l|}{ ASA, $n(\%)$} \\
\hline 1 & $10(62.5)$ \\
\hline II & $6(37.5)$ \\
\hline III & $0(0)$ \\
\hline \multicolumn{2}{|l|}{ Symptoms, n (\%) } \\
\hline Asymptomatic & $3(18.8)$ \\
\hline Cough & $6(37.5)$ \\
\hline Shortness of breath & $5(31.3)$ \\
\hline Chest pain & $4(25.0)$ \\
\hline Orthopnoea & $3(18.8)$ \\
\hline Body weakness & $1(6.3)$ \\
\hline \multicolumn{2}{|l|}{ Imaging assessment } \\
\hline Major vessel invasion & $3(25.0)$ \\
\hline $\begin{array}{l}\text { Upper airway compression \& major } \\
\text { vessel invasion }\end{array}$ & $1(8.3)$ \\
\hline
\end{tabular}

IQR, interquartile range.
Table 2 Surgical variables

\begin{tabular}{|c|c|}
\hline Variables & Value, n (\%) \\
\hline Tumor size, cm (mean, IQR) & $11.9(8.2-15.8)$ \\
\hline Mediastinal mass syndrome (MMS) & $5(31.3)$ \\
\hline Tumor size in MMS, cm (mean, IQR) & $17.0(13.0-19.1)$ \\
\hline \multicolumn{2}{|l|}{ Biopsy } \\
\hline Yes & $11(68.8)$ \\
\hline No & $5(31.2)$ \\
\hline \multicolumn{2}{|l|}{ Chemotherapy } \\
\hline Definitive & $3(18.8)$ \\
\hline Neoadjuvant & $4(25.0)$ \\
\hline Adjuvant & $3(18.8)$ \\
\hline None & $6(37.5)$ \\
\hline Operated & $12(75.0)$ \\
\hline Not operated & $4(25.0)$ \\
\hline \multicolumn{2}{|l|}{ Types of surgery } \\
\hline Elective & $11(91.7)$ \\
\hline Emergency & $1(8.3)$ \\
\hline VATS & $3(25.0)$ \\
\hline Sternotomy & $2(16.6)$ \\
\hline Thoracotomy & $3(25.0)$ \\
\hline Sternothoracotomy & $3(25.0)$ \\
\hline En bloc chest wall excision & $1(8.3)$ \\
\hline Operating duration, min (mean, IQR) & $270.8(180-322.5)$ \\
\hline Blood loss, mL (mean, IQR) & $883.3(125-950)$ \\
\hline Postoperative extubation & $10(83.3)$ \\
\hline ICU admission & $7(58.3)$ \\
\hline Length of stay, day (mean, IQR) & $12.6(5.25-19)$ \\
\hline \multicolumn{2}{|l|}{ Complications } \\
\hline Minor & $2(16.3)$ \\
\hline Major & $1(8.3)$ \\
\hline \multicolumn{2}{|l|}{ Postoperative mortality (days) } \\
\hline$<30$ & $0(0)$ \\
\hline$>30$ & $2(16.7)$ \\
\hline
\end{tabular}

IQR, interquartile range; VATS, video-assisted thoracoscopic technique. 
Table 3 Histopathological variant

\begin{tabular}{ll}
\hline Pathological variables & $\mathrm{n}(\%)$ \\
\hline Thymoma & $6(37.5)$ \\
A & 3 \\
AB & 1 \\
B2 & 2 \\
Thymic carcinoma & $2(12.5)$ \\
Germ cell tumor & $4(25.0)$ \\
Mature cystic teratoma & 3 \\
Yolk sac tumor & 1 \\
Lymphoma & $3(18.8)$ \\
Lipoma & $1(6.3)$ \\
\hline
\end{tabular}

to surgery. The patient with NSGCT had elevated $\alpha$-fetoprotein and underwent neoadjuvant chemotherapy before surgery (Figure 1).

Out of 16 patients with large mediastinal mass, 12 underwent surgery. Eleven surgeries were elective while $1(8.3 \%)$ was an emergency. The surgical approach used was by open method in 10 patients $(83 \%)$ (thoracotomy: 4, sternothoracotomy: 3 , sternotomy: 2 , en-bloc chest wall resection: 1) while 3 patients underwent video-assisted thoracoscopic surgery (Table 2). Four patients underwent lobectomy together with the excision of tumor, while 2 patients required innominate vein ligation. One patient needed major resection of the chest wall including the manubrium, clavicle, right $1^{\text {st }}$ to $3^{\text {rd }}$ rib resection on top of lobectomy and tumor debulking. None of the patients required major blood vessel replacement or cardiopulmonary bypass (CPB).

The mean duration of surgery was 270.8 minutes (IQR, 180-322.5 minutes) with average blood loss of $900 \mathrm{~mL}$ (IQR, 125-950 mL). Ten out of $12(83.3 \%)$ operated patients were extubated immediately after surgery. Seven patients $(58.3 \%)$ were admitted to intensive care unit for average duration of 2.4 days. The mean length of postoperative stay was 12.6 days (IQR, 5.25-19 days). Two patients developed surgical site infection after surgery. There was no postoperative mortality recorded within 30 days of surgery. 1 of the patients developed fatal postoperative complication of pericardial decompression syndrome and died on day 37 after surgery. The other patient died 6 months after surgery due to pulmonary embolism while he was undergoing adjuvant chemotherapy.
The final histologic diagnoses (Table 3) were: thymoma $(\mathrm{n}=6,37.5 \%)$ with its subtype $\mathrm{A}(\mathrm{n}=3), \mathrm{AB}(\mathrm{n}=1), \mathrm{B} 2(\mathrm{n}=2)$; thymic carcinoma $(n=2,12.5 \%)$; germ cell tumor $(n=4$, $25 \%)$ : mature cystic teratoma $(\mathrm{n}=3)$ and yolk sac tumor $(n=1)$; lymphoma $(n=3,18.8 \%)$; lipoma $(n=1,6.3 \%)$. Complete resection with clear margin was achieved in 9 out of $12(75 \%)$ patients.

\section{Discussion}

In this cohort, large mediastinal mass predominantly occurred in young male adults of less than 40 -year-old. Patients with large mediastinal mass are prone to develop MMS, which is defined as acute respiratory and hemodynamic decompensation due to mechanical compression of mediastinal structures. Hence, the larger the mass is, the more complicated the surgery will be. Five patients (31.3\%) with an average tumor size of $17 \mathrm{~cm}$ developed MMS in this series. The exact incidence of MMS in large anterior mediastinal mass is unknown (4).

CECT thorax is our primary choice of imaging modality to evaluate the mass. Features that may indicate malignant lesion are heterogenous, multilobulated mass with calcified foci, nodular contour and ill-defined margin with adjacent structures invasion. Thymomas appear as encapsulated, well-defined, soft tissue mass with haemorrhage, necrosis or cystic formation (5). Seminomas generally present as large, lobulated, mildly enhancing, homogeneous, noncalcified soft-tissue masses. Conversely, NSGCT tend to be more heterogeneous, with ill-defined margins, and may contain areas of necrosis and haemorrhage. Teratoma appears as well-defined lobulated cystic lesion with fluid, soft tissue and fat attenuation (6). It is critical to assess the vasculature of the tumor, association and possible encasement of adjacent large vessels such as pulmonary vessels, aorta, and vena cava to ascertain the course of treatment. We found $33 \%$ of the patients who underwent surgery had vascular involvement in the CECT, with 1 of it compressing the airway as well. There are studies that suggest magnetic resonance imaging (MRI) provide more accurate assessment of mediastinal invasions and in distinguishing between benign or malignant lesion (7). In our setting, due to limited resources and long acquisition time resulting in breathing artefacts, we reserve MRI for patients that have allergy towards contrast media or impaired renal function. Positron emission tomography (PET) scan adds only slight information in terms of anatomical assessment of the mediastinal mass compared to CT scans, but it is a better 
imaging modality for staging of lymphoma in terms of detection of intranodal and extranodal disease (8).

Obtaining a tissue biopsy for mediastinal mass remains controversial (9). National Comprehensive Cancer Network (NCCN) on thymoma and thymic carcinoma proposed that biopsy should be avoided if the lesion is resectable (10). In the circumstances where there is a suspicion of lymphoma, germ cell tumor or an irresectable tumor by CECT thorax or biochemical markers, a biopsy is indicated (11). In our practise, we do not routinely biopsy patients with resectable mediastinal mass of thymic origin based on CECT thorax to prevent tumor dissemination. The two patients with resectable thymomas were biopsied prior to referral to our centre.

Neoadjuvant chemotherapy is useful in reducing tumor volume and extent of invasion in cases deemed not suitable for primary resection. Few studies demonstrated that neoadjuvant treatment may improve complete resection rate and improve overall and recurrence-free survival in large thymomas $(12,13)$. For mediastinal NSGCT, the treatment of choice will be neoadjuvant chemotherapy followed by surgical resection after the tumor markers normalise. In our series, 4 patients with mediastinal mass invading and encasing major blood vessels were given neoadjuvant chemotherapy. Three of these patients with NSGCT underwent successful surgical resection after chemotherapy with clear margin obtained. The other patient with poorly differentiated squamous cell ca of thymus had tumor progression while on chemotherapy and was not amenable for surgery.

Pre-operative multidisciplinary meeting with intensivist and anaesthetist is important to determine the manner of intubation, the mode of ventilation and the usage of muscle relaxant during induction. In patients with signs of superior vena cava syndrome, venous access should be obtained over the lower rather than upper extremity. It was suggested the usage of spontaneous ventilation combined with awake fibre optic intubation in reducing risk of airway collapse along with short acting medications for precise control of anaesthesia level $(4,14)$.

Median sternotomy is the approach of choice in our centre for large anterior mediastinal tumors. Although VATS has become increasingly popular in thoracic surgery, it is still not suitable for large mediastinal mass in view of confined space containing many vital structures and concerns of achieving oncological clearance $(15,16)$. However, it is not an absolute contraindication to perform VATS in large mediastinal tumors. We performed 3 VATS procedures in patients with thymoma with tumor size of 6.8 to $8 \mathrm{~cm}$ with CECT findings of clear resection planes and achieved complete tumor resection.

CPB support during resection of large mediastinal mass need to be selectively applied. The usage is indicated in masses involving the aorta, pulmonary vessels or the cardiac structures. The risks of $\mathrm{CPB}$ usage include bleeding from surgical field due to full heparinization, intraoperative tumor spilling causing distant metastasis, immunomodulatory effect to the patient and carries higher risk of pulmonary failure and prolonged ventilation (17). In our experience, none of the patient underwent CPB before surgery. Out of the 12 patients, a patient underwent debulking of tumor due to intraoperative findings of ascending and descending aorta tumor infiltration along with the main pulmonary artery. Even with CPB, R0 cannot be achieved in this scenario.

Negative margin was achieved in $75 \%$ of our patients with large anterior mediastinal mass, comparable to a mediastinal tumor series by Gross et al. which reported $69.1 \%$ complete resection rate (18). There are no other large anterior mediastinal mass series for comparison at the time of writing. No major vessel replacement or lung resection required in these negative margin tumors. Amongst the 3 patients with positive margin, the $1^{\text {st }}$ patient had tumor adhered to aorta and main pulmonary artery at the aortopulmonary window. The $2^{\text {nd }}$ patient had tumor densely adhered to the right hilar requiring pneumonectomy to achieve R0 but due to the presence of hemopericardium and multiple intrapericardial nodules, decision was made to avoid pneumonectomy. The $3 \mathrm{rd}$ patient also required a left pneumonectomy to achieve R0, however patient was unstable intraoperatively with increasing inotropic requirement due to sudden decompression of the heart after tumor mobilisation. Hence, decision was made for tumor debulking avoiding pneumonectomy. All the 3 patients with positive margins received adjuvant chemotherapy after surgery.

The rate of surgical site infection was $16 \%$ (2 patients) and both were superficial. There was no reported 30 days postoperative mortality. Cohen et al. in his mediastinal tumor series with mean tumor size of $7.64 \mathrm{~cm}$ reported an overall morbidity of $20.4 \%$ and 4 mortalities out of 230 patients (19). There were $2(16.7 \%)$ recorded death after 30 days surgery due to pericardial decompression syndrome $(20,21)$ and pulmonary embolism, respectively. This data demonstrated that the morbidity and mortality rate in these series were small, supporting surgical resection as the therapy of choice for these lesions after appropriately worked up.

This review is limited by the relatively small number of patients with large anterior mediastinal mass operated over 
the period of 2 and a half year. Survival analysis could not be done because of various pathologies involved. A follow-up review at the $5^{\text {th }}$ and $10^{\text {th }}$ year mark would give a better idea on surgeries performed in these patients for the respective pathologies. Nevertheless, the findings in this series could be a reference in the management of large mediastinal mass.

\section{Conclusions}

Published data on surgery in large anterior mediastinal mass remains limited. Positive outcome of definitive surgery in this series suggests clinical feasibility with acceptable shortterm safety. Multidisciplinary approach with adequate preoperative preparations, intraoperative preparation and short- and long-term postoperative care were key features to successful treatment of this disease.

\section{Acknowledgments}

Funding: None.

\section{Footnote}

Reporting Checklist: The authors have completed the STROBE reporting checklist. Available at https://ccts. amegroups.com/article/view/10.21037/ccts-20-119/rc

Data Sharing Statement: Available at https://ccts.amegroups. com/article/view/10.21037/ccts-20-119/dss

Peer Review File: Available at https://ccts.amegroups.com/ article/view/10.21037/ccts-20-119/prf

Conflicts of Interest: All authors have completed the ICMJE uniform disclosure form (available at https://ccts. amegroups.com/article/view/10.21037/ccts-20-119/coif). The authors have no conflicts of interest to declare.

Ethical Statement: The authors are accountable for all aspects of the work in ensuring that questions related to the accuracy or integrity of any part of the work are appropriately investigated and resolved. This is a retrospective analysis of cases that were operated in our hospital. The ethical approval and the informed consent for publication of this manuscript are waived from ethics committee. The study was conducted in accordance with Declaration of Helsinki (as revised in 2013).
Open Access Statement: This is an Open Access article distributed in accordance with the Creative Commons Attribution-NonCommercial-NoDerivs 4.0 International License (CC BY-NC-ND 4.0), which permits the noncommercial replication and distribution of the article with the strict proviso that no changes or edits are made and the original work is properly cited (including links to both the formal publication through the relevant DOI and the license). See: https://creativecommons.org/licenses/by-nc-nd/4.0/.

\section{References}

1. Davis RD, Oldham HN, Sabiston DC. Primary cyst and neoplasms of the mediastinum: recent changes in clinical presentation, methods of diagnosis, management and results. Ann Thorac Surg 1987;44:229-37.

2. Temes R, Chavez T, Mapel D. Primary mediastinal malignancies: findings in 219 patients. West J Med 1999;170:161-6.

3. Erşen E, Kılıç B, Kara HV, et al. Comparative study of video-assisted thoracoscopic surgery versus open thymectomy for thymoma and myasthenia gravis. Wideochir Inne Tech Maloinwazyjne 2018;13:376-82.

4. Li WW, van Boven WJ, Annema JT, et al. Management of large mediastinal masses: surgical and anesthesiological considerations. J Thorac Dis 2016;8:E175-E184.

5. Kim JH, Goo JM, Lee HJ. Cystic tumors in the anterior mediastinum: radiologic-pathological correlation. J Comput Assist Tomogr 2003;27:714-23.

6. Juanpere S, Cañete N, Ortuño P, et al. A diagnostic approach to the mediastinal masses. Insights Imaging 2013;4:29-52.

7. Webb WR, Gatsonis C, Zerhouni EA, et al. CT and MR imaging in staging non-small cell bronchogenic carcinoma: report of the Radiologic Diagnostic Oncology Group. Radiology 1991;178:705-13.

8. Duwe BV, Sterman DH, Musani AI. Tumors of the mediastinum. Chest 2005;128:2893-909.

9. Ettinger DS, Akerley W, Bepler G. Thymic malignancies. J Natl Compr Canc Netw 2010;8:1302-15.

10. The NCCN Thymomas and Thymic Carcinomas. National Comprehensive Cancer Network, Inc., 2018

11. Singhal S, Shrager JB, Rosenthal DI. Comparison of stages I-II thymoma treated by complete resection with or without adjuvant radiation. Ann Thorac Surg 2003;76:1635-41.

12. Lucchi M, Van Schil P, Schmid R. Thymectomy 
for thymoma and myasthenia gravis. A survey of current surgical practice in thymic disease amongst EACTS members. Interact Cardiovasc Thorac Surg 2012;14:765-70.

13. Riely GJ, Huang J. Induction therapy for locally advanced. J Thorac Oncol 2010;5:S323-6.

14. Erdös G, Tzanova I. Perioperative anaesthetic management of mediastinal mass in adults. Eur J Anaesthesiol 2009;26:627-32.

15. Girard N, Mornex F, Van Houtte P. Thymoma: a focus on current therapeutic management. J Thorac Oncol 2009;4:119-26.

16. Youssef SJ, Louie BE, Farivar AS. Comparison of open and minimally invasive thymectomies at a single institution. Am J Surg 2010;199:589-93.

doi: 10.21037/ccts-20-119

Cite this article as: Ahmad A, Sathiamurthy N, Dharmaraj B, Balasubbiah N, Nguk Chai D, Nik Mohamed Kamil A, Thiagarajan M. Surgery in large anterior mediastinal mass: case series of Hospital Kuala Lumpur. Curr Chall Thorac Surg 2021;3:14.
17. Hazzard C, Kaufman A, Flores R. Mediastinal Tumors. Thorac Oncol 2018:550-4.

18. Gross JL, Rosalino UA, Younes RN, et al. Characteristics associated with complete surgical resection of primary malignant mediastinal tumors. J Bras Pneumol 2009;35:832-8.

19. Cohen AJ, Thompson L, Edwards FH, et al. Primary cysts and tumors of the mediastinum. Ann Thorac Surg 1991;51:378-84; discussion 385-6.

20. Diong NC, Dharmaraj B, Joseph CT, et al. Growing teratoma syndrome of mediastinal nonseminomatous germ cell tumor. Ann Thorac Med 2020;15:38-40.

21. Prabhakar Y, Goyal A, Khalid N, et al. Pericardial decompression syndrome: A comprehensive review. World J Cardiol 2019;11:282-91. 